\title{
Top-Down Constitutional Conventions
}

\author{
Adam Perry ${ }^{\star}$ and Adam Tucker ${ }^{\dagger}$
}

\begin{abstract}
Many scholars think that all conventions of the constitution emerge from the bottom up, out of the practices of constitutional actors. Here we develop the first systematic account of conventions that are imposed from the top down, through prescriptions by constitutional actors. We show that 'top-down conventions' (as we term them) can be created through the use of normative rule-making powers; that powers of the right kind are sometimes conferred by 'bottom-up conventions'; that these powers are often exercised; and, as a result, that top-down conventions are increasingly common. We show, too, that as the formal, systematic, and intentional products of a small number of constitutional actors, top-down conventions are a potentially illegitimate form of constitutional regulation.
\end{abstract}

KEYWORDS - convention, constitution, social rule, power, legitimacy

\section{INTRODUCTION}

It used to be said that ours is a "historic" constitution: the constitution is the product of evolution, not deliberate design; it emerges from the bottom up, rather than being developed from the top down. This is no longer true, if it ever was. Over the past 20 years, the pace of deliberate constitutional change has been relentless. The most obvious changes have been to the legal part of the constitution. Parliament has expanded human rights protections, regionalized power, and upended ancient institutions

\footnotetext{
^Associate Professor, Faculty of Law, University of Oxford; Garrick Fellow \& Tutor, Brasenose College.

tSenior Lecturer, School of Law and Social Justice, University of Liverpool. We thank Veronica Fikfak, Michael Gordon, Tara Leigh Grove, Joseph Jaconelli, William Partlett, and Ewan Smith for their helpful comments. We also thank audiences at the universities of Auckland, Lancaster, Manchester, Melbourne, and Oxford.

1 The term is used by A.V. Dicey in his unpublished lectures on the Comparative Study of Constitutions. We owe the reference to V. Bogdanor, The Monarchy and the Constitution (Oxford: Oxford University Press, 1995) 64.
} 
in a series of grand constitutional statutes. Judges, meanwhile, have been busy developing common law constitutional rights and positioning the rule of law as a counterweight to parliamentary sovereignty ${ }^{2}$. These legal changes have understandably held scholars' attention.

What has gone relatively unnoticed is a parallel trend in the non-legal, conventional part of the constitution. Constitutional conventions traditionally emerge from the bottom up, out of the practices of constitutional actors. The convention that requires the monarch to do as her ministers advise is a 'bottom-up convention', for example, as is the convention that entitles the monarch to advise, encourage, and warn her ministers. Many scholars maintain that all conventions of the constitution are bottom-up conventions. They deny that there are or could be conventions created from the top down, through the exercise of rule-making powers held by constitutional actors.

In this article we develop the first systematic account of 'topdown conventions'. The first part of our account is descriptive and conceptual. We show that top-down conventions are made possible through a certain kind of normative rule-making power; that powers of the right kind are conferred by some bottom-up conventions; that these powers are often used; and as a result that top-down conventions are ubiquitous. Many rules of the Ministerial Code, for example, derive from a convention that gives the Prime Minister the authority to make rules which bind ministers. Many inter-governmental rules, including in the devolution context, owe their existence to a convention that empowers institutions to bind themselves. The second part of our account is normative. We begin to develop an account of the desirability of constitutional conventions which is differentiated between the different kinds of convention identified in our first part. On the one hand, we suggest that bottom down constitutional conventions are modestly virtuous. But on the other hand, we come to sceptical conclusions about the value of topdown constitutional conventions.

\footnotetext{
2 See, eg, R (Evans) v Attorney General [2015] UKSC 21, [2015] AC 1787; Jackson v Attorney General [2005] UKHL 56, [2006] 1 AC 262.
} 


\section{CONVENTIONS}

The British constitution, like all constitutions, consists of rules. What makes a rule a part of the constitution? Two conditions are necessary, and for present purposes we can treat them as sufficient. ${ }^{3}$ First, the rule must have a constitutional character. That means the subjects of the rule - those to whom it applies - must be either constitutional actors qua constitutional actors (monarch, minister, judge, etc) or institutions of government (House of Commons, Supreme Court, local government, etc). Also, the rule must be of constitutional importance. ${ }^{4}$ The rules regulating the Court of Appeal's jurisdiction are likely constitutional, for example, whereas the rules about the Court of Appeal's vacations are almost certainly not. The line between rules that have a constitutional character and rules that do not is, of course, difficult to draw exactly; but, it is enough that the line exists and that there are clear instances on each side.

The second condition is about ownership, and it takes more explaining. Any rule exists by virtue of certain facts. These facts are the grounds of the rule. Some rules are grounded in the fact of a special kind of social practice; these are social rules. Some rules are grounded in the fact of a prescription made by someone with a special kind of power; these are prescribed rules. Finally, some rules are grounded in their legitimacy, ie, the fact they ought to be used as a guide to conduct; such rules are legitimate rules. In theory, a rule might be merely legitimate. Perhaps some moral rules are like this. Such a rule does not have a social existence: it is not grounded in people's thoughts or actions. People might never have heard of the rule, let alone have 'engaged' with it. ${ }^{5}$ Plainly the rules of the

\footnotetext{
${ }^{3}$ Here we are restricting ourselves to rules that regulate conduct, rather than rules that create governmental institutions.

${ }^{4}$ The analogy here is to the subject matter of constitutional statutes. See, eg, A. King, Does the United Kingdom Still Have a Constitution? (London: Sweet \& Maxwell, 2001) 1; P. Craig, 'Constitutionalising Constitutional Law: HS2' [2014] PL 373, 389-390; F. Ahmed and A. Perry, 'Constitutional Statutes' (2017) 37 OJLS 461. For certain conventions to exist, they must be regularly observed, and thus possess a degree of practical importance. See text at $\mathrm{n} 10$ below.

5 A term we borrow from J. Gardner, 'Legal Positivism: 5 1/2 Myths' (2001) 46 American Journal of Jurisprudence 199, 200.
} 
British constitution are not like this. The constitution is our constitution. Its rules are our rules, and they are our rules because they are grounded in what constitutional actors here think and do. The rules of the constitution may be legitimate, but they cannot be merely legitimate. The rules of the constitution must be either practised or prescribed by constitutional actors.

Of the rules which belong to the constitution, some are legal rules while others are non-legal rules. Since A.V. Dicey's Introduction to the Law of the Constitution, the traditional name for a non-legal rule of the constitution has been a 'convention of the constitution'. The name is apt to mislead, however. In ordinary and (especially) philosophical contexts, 'convention' suggests something that is usually or normally done. ${ }^{7}$ With this sense of 'convention' in mind, one might assume that all conventions of the constitution are grounded in a practice, and hence that all conventions are social rules. Were this assumption correct, a prescription could never ground a convention on its own. That is in fact what many scholars think. It is not, however, what all scholars think - and it is not what we think.

We have no desire to break with established usage, but we need to be careful to avoid confusion. So we shall use the term convention to refer to any non-legal constitutional rule, regardless of grounding. And we shall stipulate that a bottom-up convention is any non-legal rule grounded in a social practice, and that a top-down convention is any non-legal constitutional rule grounded in a prescription.

\section{BOTTOM-UP CONVENTIONS}

We will argue in the next section that top-down conventions are made possible by bottom-up conventions of a certain type. To

\footnotetext{
6 A.V. Dicey, Introduction to the Study of the Law of the Constitution (London: Macmillan, 8th ed, 1915) 277.

${ }^{7}$ eg, D. Lewis, Convention: A Philosophical Study (Oxford: Blackwell, 2002). Joseph Jaconelli and Mark Elliott both seem to think that conventions of the constitution must be conventions in Lewis's sense: J. Jaconelli, 'The Nature of Constitutional Convention' (1999) 19 LS 24, 39-40; M. Elliott, 'Parliamentary Sovereignty and the New Constitutional Order: Legislative Freedom, Political Reality and Convention' (2002) 22 LS 340, 361.
} 
show that there are bottom-up conventions of this type, we need a rough-and-ready account of the practice that grounds a bottom-up convention. This section provides that account.

We shall start with Sir Ivor Jennings' test for bottom-up conventions in The Law and the Constitution. According to Jennings, when we want to know whether there is a convention,

[w]e have to ask ourselves three questions: first, what are the precedents; secondly, did the actors in the precedents believe that they were bound by a rule; and thirdly, is there a reason for the rule? A single precedent with a good reason may be enough to establish the rule. A whole string of precedents without such a reason will be of no avail, unless it is perfectly certain that the persons concerned regarded themselves as bound by it. ${ }^{8}$

The first two questions ask whether a non-legal rule is grounded in a type of practice. That practice consists of a behavioural element (the 'precedents') and an attitudinal element (the actors' belief they are bound by a rule). The third question asks whether there is a reason for the putative rule, and thus about the rule's legitimacy. Jennings does not explicitly say that these questions are only about constitutional rules, but the point is implied from the context.

The quoted passage is not as clear as it might be, so let us set out how we understand it. Jennings is sometimes taken to claim that there is a convention if and only if all three of his questions are answered 'yes'. This would have two consequences. The first is that practice would be insufficient to ground a convention. Practice would suffice only in combination with a reason. As the last sentence of the quoted passage suggests, however, and as other passages confirm, Jennings thought that practice alone could ground a convention. ${ }^{9}$ Whether a rule is supported by a reason is

\footnotetext{
8 Sir I. Jennings, The Law and the Constitution (London: University of London Press, 4th ed, 1952) 136. Jennings' test has been endorsed by courts in Canada (Reference re: Resolution to Amend the Constitution, [1981] 1 SCR 753, 888), India (Supreme Court Advocates-on-Record Association v Union of India, (1993) 4 SCC 441, [444]), and recently in the UK (Evans v Information Commissioner [2012] UKUT 313 at [75] (AAC).

9 ibid 135.
} 
relevant only to the strength of the practice (eg, the number of precedents) it takes to ground a convention. The second consequence is that practice would be necessary for there to be a convention. But this is not what Jennings believed either. It is clear from his remarks elsewhere that Jennings thought that there are some top-down conventions, and thus some conventions that are not grounded in practice. ${ }^{10}$

Jennings is therefore best read as claiming that a certain practice is sufficient but unnecessary to ground a convention. Schematically, the idea is that there is a convention that $A$ s ought to $B$ if (1) $A$ s $B$ often enough, and (2) enough constitutional actors believe there is a convention that $A$ s ought to $B$ (where $A$ s are members of some class of constitutional agent, and $B$ is an act of constitutional importance). What counts as 'enough' precedents or 'enough' actors is left vague, but it will depend at least partly on whether there is a reason for a convention that $A$ s ought to $B$. Because any rule that satisfies this test is grounded in a practice, it is a test for a bottom-up convention. Let us call it Jennings' Test.

There is much to like about Jennings' Test. In particular, it correctly states that the practice that grounds a bottom-up convention has a behavioural element and an attitudinal element. But Jennings' Test has a flaw, which is that it misdescribes the attitudinal element. The test says that a convention is the product of a belief that the rule that is the convention is binding. So it says that a convention is the product of a belief that the rule that is the convention already exists (ie, before the formation of the belief). This belief would necessarily have been mistaken when formed. Consider the convention that monarchs ought to do as their ministers advise, which Rodney Brazier terms the 'Cardinal Convention'. ${ }^{11}$ Jennings' Test would say that the Cardinal Convention arose from the mistaken belief that the convention already existed. Surely this is not right. Conventions are not always the result of misapprehensions of conventions; those whose beliefs

\footnotetext{
10 See, especially, Jennings' discussion of conventions governing Commonwealth relations: $\mathrm{n} 8$ above, 97, 98-99.

${ }^{11}$ R. Brazier, Constitutional Practice: The Foundations of British Government (Oxford: Oxford University Press, 3rd ed, 1999) 178.
} 
help bring conventions into existence are not always open to criticism for holding those beliefs.

To correct this flaw in Jennings' Test, we need a better account of the attitudinal element of the practice that grounds a convention. This is easier than it might seem. When Jennings formulated his test, there were no well-developed theories of social rules. We can do better now. Several decades after Jennings wrote The Law and the Constitution, H.L.A. Hart published The Concept of Law. There Hart set out a new theory of social rules, which has dominated thinking about social rules in jurisprudence ever since. ${ }^{12}$ Like Jennings, Hart thought that a social rule (such as a bottom-up convention) is grounded in a practice consisting of a behavioural element and an attitudinal element. And, like Jennings, Hart thought of the behavioural element as a pattern of general conformity with the putative rule. But unlike Jennings, Hart did not think of the attitudinal element as a belief in a binding rule. Instead Hart said the attitude that helps ground a social rule is a 'critical reflective attitude' which he called 'acceptance'.

What is acceptance? Hart's own remarks are somewhat sketchy, but recently one of us has built on Hart's work to try to give a satisfactory answer. ${ }^{14}$ The attitude that helps ground a social rule is acceptance of the proposition that is the content of the rule. Thus, the social rule that $A$ s ought to $B$ is partly grounded in the acceptance that $A$ s ought to $B$. To accept a proposition is to treat it as true (to proceed on the basis that it is true, to take it for granted). What it means to treat a proposition as true depends on the context. To treat it as true that $A$ s ought to $B$ may, for example, include praising $A$ s for Bing; criticising $A$ s for not Bing; acknowledging the legitimacy of like praise and criticism by others; and using normative language (eg, 'ought', 'wrong') to express these reactions. Acceptance has other features, in addition to how it displays itself. The two features that will matter for our purposes are, first, that acceptance is under a person's control - it is up you

12 H.L.A. Hart, The Concept of Law (L. Green (ed), Oxford: Oxford University Press, 3rd ed, 2012) 56-58, 255-57. Jaconelli was the first to note the connection between Jennings' Test and Hart's account of social rules: $n 7$ above, 28-31. 13 ibid 57.

${ }^{14}$ A. Perry, 'The Internal Aspect of Social Rules' (2015) 35 OJLS 283. 
what to accept and what not to accept; and, second, that acceptance is responsive to practical reasons.

Putting these points together, there is a bottom-up convention that $A$ s ought to $B$ if and only if (1) $A$ s $B$ often enough, and (2) enough constitutional actors accept that $A$ s ought to $B$. The Cardinal Convention, for example, is grounded in the fact that monarchs do as their ministers advise and that constitutional actors accept that monarchs ought to do as their ministers advise. There is no suggestion here of a mistaken belief (indeed, no suggestion of any belief), so the flaw in Jennings' Test is avoided. Much more could be said about the practices that ground bottomup conventions. However, this is all we need to know about bottom-up conventions to explain top-down conventions, to which we now turn.

\section{TOP-DOWN CONVENTIONS}

Everyone can agree that top-down conventions are possible in principle. There is nothing impossible about grounding a non-legal rule of the constitution in a prescription. After all, non-legal rules are grounded in prescriptions in other contexts (games, corporations, religion, etc); why not in the constitutional context, too? Some scholars go further and claim that there are in fact topdown conventions. That is what Jennings thought, as we said. ${ }^{15}$ Kenneth Wheare granted that most conventions arise from the bottom up, but added that:

a convention may arise much more quickly .... There may be an agreement among the people concerned to work in a particular way and to adopt a particular rule of conduct. This rule has not arisen from custom; it has no previous history as a usage. ${ }^{16}$

\footnotetext{
15 See text and references at $\mathrm{n} 10$ above.

${ }^{16}$ K. Wheare, Modern Constitutions (Oxford: Oxford University Press, 1951) 180.
} 
Geoffrey Marshall ${ }^{17}$, O. Hood Phillips ${ }^{18}$, Eric Barendt ${ }^{19}$, Brazier $^{20}$, Andrew Heard ${ }^{21}$, and many other scholars acknowledge that there are top-down conventions. Parliamentarians also regularly assume that conventions can be grounded in prescriptions. The 2006 report on The Governance of Britain, for example, took for granted that the House of Commons could choose to 'develop' a 'parliamentary convention' requiring the Commons' approval of certain uses of the war powers prerogative. ${ }^{22}$ Until recently, probably the dominant view was that top-down conventions exist alongside bottom-up conventions.

Sometime in the 1990s or early 2000s, the tide began to turn. There are more and more top-down sceptics, who say that there are no top-down conventions, and more strongly that no one has the power to create a top-down convention (as opposed to having such a power and not using it). The sceptics can now count among their number Nicholas Aroney ${ }^{23}$, Mark Elliott ${ }^{24}$, Joseph Jaconellii ${ }^{25}$, Aileen $\mathrm{McHarg}^{26}$, and Adam Tomkins ${ }^{27}$, among others. McHarg says that if we 'recognis[e] the importance of practice' we shall see that constitutional actors and institutions 'cannot unilaterally create

17 G. Marshall, 'What are Constitutional Conventions?' (1985) 38 Parliamentary Affairs 33, 38.

18 O. Hood Phillips and P. Jackson, O. Hood Phillips' Constitutional and Administrative Law (London: Sweet \& Maxwell, 7th ed, 1987) 120.

${ }^{19}$ E. Barendt, Constitutional Law (Oxford: Oxford University Press, 1999) 43.

20 S. de Smith and R. Brazier, Constitutional and Administrative Law (London: Penguin, 1998) 42.

21 A. Heard, Canadian Constitutional Conventions (Don Mills: Oxford University Press, 2nd ed, 2014) 7-11.

22 Governance of Britain, Report Cm 7170 (2007) at [29].

23 N. Aroney, 'Law and Convention' in B. Galligan and S. Brenton (eds), Constitutional Conventions in Westminster Systems: Controversies, Changes, and Challenges (Cambridge: Cambridge University Press, 2015) 32.

${ }^{24}$ Elliott $n 7$ above, 361 .

25 Jaconelli $n 7$ above, 39-42.

26 A. McHarg, 'Reforming the United Kingdom Constitution: Law, Convention, and Soft Law' (2008) 71 MLR 853, 857-861.

27 C. Turpin and A. Tomkins, British Government and the Constitution (Cambridge: Cambridge University Press, 7th ed, 2011) 191; A. Tomkins, 'A West Lothian Answer?' (Scottish Constitutional Futures Forum, 28 March 2013) at <https://goo.gl/27dsXD> (last accessed 21 December 2017). 
binding constitutional rules ${ }^{28}$. Jaconelli says that the 'real essence' of any convention is a 'system of concordant actions and expectations ${ }^{29}$, ie, a type of practice. Similar claims can be found in recent parliamentary reports. The McKay Commission, for example, hoped that there would arise a convention requiring the consent of English MPs to 'English laws', but cautioned that it 'has to emerge from practice', and cannot 'be created at the will of a government'. ${ }^{30}$

This sceptical trend notwithstanding, there are top-down conventions, as we shall show. Even if you are not a top-down sceptic, what follows is of importance, because it contains a novel argument for the existence of top-down conventions.

\section{Rules and Powers}

To recall, a top-down convention is a kind of prescribed rule, and thus the product of a kind of power. Let us start there, with the kind of power at issue. One kind of power is influence: the ability to affect people's reasons and their beliefs about their reasons. ${ }^{31}$ Influence may be exercised by shaping circumstances so as to make it easier for people to achieve some goals rather than others, or to convince people to adopt certain goals in the first place. Influence may be exercised through declarations and orations, or through action other than speech, such as by setting an example. Influence has many uses, among them the creation of social rules. Suppose a group of wealthy people declare that they will give most of their money to charity after they die. They encourage others to do the same. Over time, there arises a social rule among the very rich that wealth ought to be donated on death. The original group of donors created a social rule - but indirectly, by causing the conditions under which there is a social rule.

\footnotetext{
${ }^{28}$ n 26 above, 862 .

${ }^{29}$ Jaconelli $n 7$ above, 42.

30 The McKay Commission, 'Report of the Commission on the Consequences of Devolution for the House of Commons' (House of Commons Library, March 2013) at <https://goo.gl/DMfBWr> (last accessed 21 December 2017). ${ }^{31} \mathrm{~J}$. Raz, Practical Reason and Norms (Princeton: Princeton University Press, rev ed, 1990) 99.
} 
Conventions can also be the product of influence. Consider the Salisbury-Addison Convention. To prevent a constitutional crisis, Lord Salisbury and Lord Addison came to the understanding that the House of Lords would give a second reading to 'manifesto bills' that originated in the House of Commons. Lord Salisbury and Lord Addison abided by this understanding themselves, and encouraged others to do so also. Over time, there arose a convention, with content similar to Lord Salisbury and Lord Addison's original accord. The two peers could be said to have created the convention - but again, they did so indirectly, by fostering the conditions under which there is a bottom-up convention. Were power as influence the only kind of power that could be used to create a convention, all conventions would be bottom-up conventions, and the top-down sceptics would be vindicated.

There is, however, a second kind of power: normative power. For present purposes, we shall adopt Joseph Raz's influential theory of normative power. ${ }^{32}$ According to Raz, you have a normative power when an act of yours is the exercise of a normative power. An act of yours is the exercise of a normative power when it meets two conditions. First, your act must create a rule directly and noncausally. The creation of the rule is the 'result" ${ }^{33}$ of the act, not its consequence, where the relationship between an act and its result is intrinsic, and the relationship between an act and its consequence is causal. Second, your act must be recognised as creating a rule because it is expected that, if it is so recognised, then you will tend to perform that act only when you intend to create a rule.

The power to contract illustrates what Raz has in mind. By performing certain acts - making representations and so on - you and another party may create a contract, and thus a legal norm. You do so directly, without any intermediate step. Your acts are the ground of the contract, not its cause; a contract is not a mere effect of the acts that give rise to it. Moreover, the law recognises certain acts as creating a contract partly because it is desirable for people to have a way to bind themselves, and it is expected that, if

32 ibid 101-103.

33 n 31 above, 103. 
the relevant acts are recognised as creating a contract, people will tend to perform those acts only when they intend to bind themselves. So, the power to contract is a normative power, which is of course the intuitive result.

The power to contract is a legal power, but normative powers also exist outside the law. Were there a normative power to create a convention, and were that power to be exercised, then there would be a top-down convention. So, the question at this point is whether there are normative powers to create conventions. The question can be narrowed by distinguishing two types of normative power and two types of convention.

\section{Subjects and Creators}

Some normative powers are powers you have to bind yourself. These are powers of voluntary commitment. An agreement (a contract, a promise, etc) is a type of voluntary commitment; so, too, is an undertaking. Now observe that some conventions bind any constitutional actor who occupies a certain role. These are rolecentred conventions. The convention that the monarch ought to grant assent to legislation is such a convention. The convention does not bind Queen Elizabeth II in particular; it binds anyone who occupies the role of monarch. Suppose that a constitutional actor makes an agreement. She has committed herself, but only herself. She has not bound future occupants of her constitutional role. Were her agreement a role-centred convention, it would bind future occupants of her role. Therefore, her agreement is not a role-centred convention. Generalizing, it is impossible for there to be a normative power the exercise of which (1) binds only yourself, and (2) creates a role-centred convention and thus binds anyone in a constitutional role.

Some top-down sceptics appear to think that this argument, or one like it, shows that there is no such thing as a normative power to create a convention. ${ }^{34}$ They would be correct were powers of

\footnotetext{
${ }^{34}$ Jaconelli n 7 above, 41: 'Agreements ... are regarded as morally (or legally, as the case may be) binding only on those who are parties to them. Yet the central idea behind constitutional conventions is the notion that they bind those who occupy for the time being the relevant offices of state, regardless of whether
} 
voluntary commitment the only kind of normative power, and were role-centred conventions the only kind of convention. Neither of these things is true, though. Some normative powers are powers to bind, not yourself (or only yourself), but others. A normative power over others is authority. ${ }^{35}$ Further, some conventions bind, not constitutional actors qua actors, but governmental institutions. These are institution-centred conventions. The conventions that regulate the relationship between the House of Commons and the House of Lords are institution-centred conventions, for example, as are the conventions that regulate the police and the army.

So we accept that a constitutional actor cannot commit only herself and thereby create a convention. That leaves open the possibility that a constitutional actor could exercise authority over others and thereby create a convention. It also leaves open the possibility that an institution could commit itself and thereby create a convention. We can now sharpen our question. Earlier we asked: are there normative powers to create conventions? But it is more perspicuous to ask: do any institutions have the power to bind themselves? And do any constitutional actors have the power to bind other constitutional actors?

\section{Power-Conferring Rules}

If an institution has the power to bind itself, or an actor has the power to bind others, then these powers must come from somewhere. It is clear where legal powers, like the power to contract, come from: they are conferred by legal rules. And it is clear where moral powers, like the power to promise, come from: moral rules. A power to create a convention does not come from law or morality. So where could it come from? Some top-down sceptics seem to assume there are no sources of normative powers other than law and morality. ${ }^{36}$ Were that correct, it would follow

they have agreed to them or not.' McHarg n 26 above, 860 makes a similar point.

35 n 31 above, 101.

${ }^{36}$ Jaconelli $\mathrm{n} 7$ above, 41 seems to assume that any agreement must be either morally or legally binding. McHarg at n 26 above, 860-861 appears to assume that, insofar as conventions are binding, they must be morally binding. 
that there are no normative powers to create conventions. But this assumption overlooks an alternate source of normative powers social rules, including conventions.

Suppose that some group has a social rule of the form: 'If $A$ says "Everyone ought to $B$ ", then everyone ought to $B$ '. And suppose that the group accepts this rule because they want $A$ to have a way to bind the group, and they expect she will not say 'Everyone ought to $B$ ' unless she wants to bind them to $B$. Then $A$ has authority over the group. ${ }^{37}$ If she exercises her authority, the result is a new rule, which says: 'Everyone ought to $B$ '. Similarly, the group might have a rule which says: 'If anyone says "I undertake to $B$ ", then that person ought to $B$ '. So long as the other conditions of a normative power are met, this social rule gives the members of the group a power to bind themselves. Here, then, are two forms of power-conferring social rules.

There are lots of everyday examples of power-conferring social rules. An authority-conferring rule is obviously at the heart of 'Simple Simon Says', a game that is constituted by social rules. A club or team might have a social rule that vests authority in the leader or captain to make decisions for the club or team as a whole (eg, when to practice, which formations to use). Or suppose that at the beginning of an academic conference panel the chair says that questions will be taken in threes and answered together. She has created a new rule for those attending the panel. She had the power to do so by virtue of a social rule amongst academic conference-goers, according to which the instructions of chairs as to questions ought to be followed.

Social rules could give governmental institutions the power to bind themselves, and certain constitutional actors the power to bind others. These social rules would be constitutional in character. Earlier we said that any social, non-legal rule of the constitution is a bottom-up convention. An alternate source of normative powers to create conventions has therefore been hiding in plain sight: the normative powers to create top-down conventions could be conferred by bottom-up conventions. This is

\footnotetext{
${ }^{37}$ Specifically, $A$ has de facto authority. If there are in fact good reasons for $A$ to have a way to bind others, then she has legitimate authority.
} 
not merely a hypothetical possibility: there are in fact bottom-up, power-conferring conventions, as we shall now explain.

\section{The Ministerial Code Convention}

The Ministerial Code (as it is now called) began its life in 1945, when Clement Attlee brought together various directives about ministerial procedure in a single document. ${ }^{38}$ The Ministerial Code became a fixture of government: a new version was prepared after each general election, and circulated to ministers. Over time, the Code expanded and grew in importance. The current version sets out standards applicable to ministers on a wide range of matters including Parliament, appointments, departments, constituency interests, relations with the media, and the presentation of policy. ${ }^{39}$

The Ministerial Code used to be regarded as a set of mere guidelines, but it is now treated as a set of binding rules by ministers, their critics, and the public. Amy Baker, in her excellent history of the Code, Prime Ministers and the Rule Book, dates this development to the Code's publication in 1992, when the Code began to be cited as an authoritative set of requirements, which ministers must comply with on pain of resignation. ${ }^{40}$ Baker writes:

The publication of [the Ministerial Code] marks a watershed in the document's history. Since its release, the media and members of Parliament have ... used [the Ministerial Code] as a strict code of conduct by which to judge and regulate ministerial behaviour. ${ }^{41}$

Baker concludes that the Code has become 'a consolidated set of rules and principles governing the constitutional conduct of ministerial office ${ }^{42}$.

\footnotetext{
38 A. Baker, Prime Ministers and the Rule Book (London: Politico's Publishing, 2000) ch 1.

${ }^{39}$ Cabinet Office, Ministerial Code (2015).

40 A. Baker, Prime Ministers and the Rule Book (London: Politico's Publishing, 2000).

41 ibid 104.

${ }^{42}$ ibid.
} 
Two examples help to show the Code's binding status. Shortly after the Code's publication, the National Heritage Secretary, David Mellor, was accused of inappropriately accepting gifts from the daughter of a prominent member of the Palestine Liberation Organisation. The shadow Heritage Minister at the time, Bryan Gould, pointed to the specific paragraph of the Ministerial Code to show that Mellor had breached the rules of his office. Lord Blake told The Times in an interview during the controversy: 'If it becomes clear that David Mellor has breached [the Ministerial Code] he should resign and he should do so without delay"33. Even Mellor's defenders framed their arguments with reference to the Code, implicitly accepting its determinative status. Eventually, Mellor did resign. ${ }^{44}$ To take a more recent example, in 2010, Baroness Warsi told the Prime Minister of allegations that arrangements for a visit she made to Pakistan had resulted in the appearance of a conflict of interest and thus a breach of the Code. The Prime Minister asked the Independent Adviser on Ministers' Interests to investigate. Ultimately his report cleared Baroness Warsi of any serious breach of the Code. ${ }^{45}$ The point, for our purposes, is that compliance with the Code was not treated as optional; it was assumed to be mandatory. ${ }^{46}$

The power to change the Ministerial Code lies with the Prime Minister. The Prime Minister can, and often does, unilaterally add to or subtract from the Code. 'It is for the Prime Minister to determine the terms of the Code. ${ }^{47}$ Moreover, while the Code

${ }^{43}$ Lord Blake, 'Tough Talk on Gift Guidelines; Diary' The Times, 24 September 1992, 12.

${ }^{44}$ For a more detailed overview of the Mellor affair, see Baker n 40 above, 7375.

45 Correspondence between Sir Alex Allan and the Prime Minister, 'Report on Investigation Under the Ministerial Code' (27 June 2012) at https://www.gov.uk/government/publications/sir-alex-allan-s-report-oninvestigation-under-the-ministerial-code (last accessed 16 April 2018). See also: M. Everett and E. Faulkner, 'The Ministerial Code and the Independent Adviser on Ministers' Interests' (House of Commons Library Briefing Paper, No 03750, 12 January 2017) 21.

$46 \mathrm{~N}$. Barber provides earlier examples along the same lines in 'Laws and Conventions' (2009) 125 LQR 295, 305.

47 'Government Memorandum in Response to the Third Report from the Public Administration Select Committee (Session 2000-2001) on the Ministerial Code' 
includes some established practices, it is not primarily descriptive. There are frequent substantive changes, designed to shape practice rather than to merely reflect it. In 1995, for example, the Code was amended to include an obligation not to 'knowingly mislead Parliament ${ }^{38}$. In 2005, the Code was amended to state that ministers 'must ... comply with the Codes of Conduct for their respective Houses and any requirements ${ }^{49}$ imposed by the Parliamentary Standards Authority. It used to be voluntary for a minister to seek advice from the Advisory Committee on Business Appointments Rules about taking up outside appointment on leaving office ${ }^{50}$. A 2007 amendment made it obligatory. ${ }^{51}$

Now let us put the pieces together, in two stages. We said earlier that there is a bottom-up convention that $A$ s ought to $B$ if (1) $A$ s $B$ often enough, and (2) enough constitutional actors accept that $A$ s ought to $B$. We know that ministers consistently do as the Code says, and that ministers (and others) accept they ought to do as the Code says. That alone shows there is a bottom-up convention that ministers ought to do as the Code says. We are not alone in this conclusion. There is a 'new convention', Nick Barber says, which imposes 'a duty on Ministers to follow the rules set out in the Code $^{52}$. We shall call this the Ministerial Code Convention.

Now for the second stage: given that the Code can be changed by the Prime Minister, the Ministerial Code Convention requires compliance with the Prime Minister's rules, when they take the form of amendments to the Code. The Ministerial Code Convention therefore confers authority on the Prime Minister over ministers. The Prime Minister exercises this authority by adding to the Code. It follows, with one qualification, that the rules the Prime Minister adds to the Code are top-down conventions. The qualification is that not all of the rules in the

(UK Parliament, 11 December 2001) at <https://goo.gl/P19xMa $>$ (last accessed 3 January 2017).

48 Everett and Faulkner n 45 above, 19.

${ }^{49}$ Currently para. 1.6 in the Ministerial Code 2015: n 39 above. The history of the amendment is described by Everett and Faulkner n 45 above, 20 .

${ }^{50}$ Governance of Britain $\mathrm{n} 22$ above, at [121].

${ }^{51}$ Everett and Faulkner n 45 above, 21.

52 Barber n 46 above, 305. 
Code have a constitutional character. The Code's rule against using official social media accounts for party political reasons is not part of the constitution, for example. The Code's rules as to ministerial conduct and private interests, by contrast, clearly do have a constitutional character, and are therefore top-down conventions. Indeed, there is reason to think that the Ministerial Code 'may now be taken as the defining constitutional document on [the] Prime Minister and Cabinet ${ }^{53}$.

There are many codes of conduct, and we do not claim that they all involve convention-based authority relationships. What matters is whether there is a bottom-up convention that requires compliance with a code, and how that code can be changed. It seems clear to us that there is no convention that requires compliance with the Guide to Judicial Conduct ${ }^{54}$, for example. On the other hand, there may be a stronger case for a convention that requires compliance with the parliamentary codes of conduct. What we have sought to show is that some conventions confer authority on constitutional actors to make rules for other constitutional actors. Now let us show that top-down conventions can also be found outside the Ministerial Code.

\section{The Institutional Agreement Convention}

In 2013 the Supreme Court and the Ministry of Justice established a concordat. The concordat sets out the division of responsibilities among the Lord Chancellor, President of the Court, and Chief Executive of the Court. It makes provision for consultation and exchange of information on appointments and remuneration, among other matters. It creates a method for resolving disputes, and a process for review and amendment. The parties declare that they 'agree to abide by the provisions and obligations ${ }^{55}$ in the concordat wherever possible.

\footnotetext{
${ }^{53}$ P. Madgwick and D. Woodhouse, The Law and Politics of the Constitution of the United Kingdom (London: Harvester Wheatsheaf, 1995) 120.

${ }^{54}$ Judges’ Council, Guide to Judicial Conduct (2018).

55 'Concordat Between: The Ministry of Justice and the Supreme Court of the United Kingdom' (The Supreme Court, 30 October 2013) at <https:/ /goo.gl/dSrPvR> (last accessed 4 January 2017).
} 
By establishing their concordat, the Supreme Court and the Ministry of Justice purported to create an agreement, and so to bind themselves. They purported to exercise a normative power. Where would they have acquired this power? Our answer should come as no surprise: from a bottom-up power-conferring convention. This bottom-up convention required the Supreme Court and the Ministry of Justice to do as they represented they would, and the two institutions triggered the convention with their concordat. The result was an agreement.

Top-down sceptics will spot an immediate problem with this answer. Any bottom-up convention has to be grounded in a practice. In 2013 there was no history of the Ministry of Justice or (especially) the Supreme Court doing as it represented it would. There was no history of acceptance that these institutions ought to live up to their representations to each other. If there is no history, there is no practice; and if there is no practice, how could there be a bottom-up convention?

The solution is to see the Supreme Court-Ministry of Justice concordat in context, as part of a series of agreements between institutions. There are rules that apply to a specific person because they apply to a class of person to which she belongs (eg, the rules of the road, the rules of etiquette). In the same way, there is a convention that requires the specific institutions that are the Supreme Court and the Ministry of Justice to keep their agreement because there is a convention that requires governmental institutions generally to live up to their representations. This convention is grounded in the long practice of institutions doing as they represent they will do, on the one hand, and of the acceptance that they ought to do so, on the other.

As evidence of this practice, consider:

1. Conference agreements. There was a series of Colonial and Imperial Conferences between 1887 and 1937. At these conferences, representatives of various governments purported to reach nonlegal agreements on aspects of Commonwealth relations. For example, even after the Statute of Westminster 1931, '[t]he position of the Governor-General ... [was] determined by 
agreements at the Conferences of 1926 and $19300^{56}$. Likewise, ' $[t]$ he system of communication and consultation between the Governments of the British Commonwealth of Nations was agreed upon ${ }^{57}$ at the same conferences. According to R.T.E. Latham, the 'conventions of co-operation' between Commonwealth states were 'for the most part planned" ${ }^{58}$. He writes that ' $[\mathrm{r}]$ eports of imperial conferences repeatedly enunciate comprehensive rules for the conduct of treaty negotiations and other matters of foreign policy ${ }^{59}$. These agreements were generally upheld, with occasional lapses.

2. Devolution agreements. Following devolution, in 1999, the UK government and the devolved governments of Northern Ireland, Scotland, and Wales issued a Memorandum of Understanding along with various supplementary agreements. The Memorandum characterizes itself as a statement of 'political intent'. The agreements in it are described as 'binding in honour'. Like the conference agreements, the devolution agreements are about intergovernmental communication, consultation, and co-operation. The best-known devolution agreement is the 'Sewel Convention', which requires the Westminster Parliament to obtain the consent of the Scottish Parliament before legislating on matters devolved to Scotland. (There are equivalent consent requirements with respect to Northern Ireland and Wales.) Other devolution agreements also have a constitutional character - the agreement to create the Joint Ministerial Committee, for example, or the agreement to co-operate on foreign and international affairs. The devolution agreements are generally abided by, again with occasional departures.

3. Other concordats. The concordat between the Supreme Court and the Ministry of Justice is one of many concordats involving departments or committees. For example, in 1932 the Treasury and the House of Commons Public Accounts Committee agreed

\footnotetext{
${ }^{56}$ Jennings n 8 above, 98-99.

57 ibid 99.

58 R.T.E. Latham, The Law and the Commonwealth (London: Oxford University Press, 1949) 158.

59 ibid.
} 
that, in general, authority for expenditures ought to flow from a specific statute, rather than from an Appropriations Act. In the words of the Constitution Committee, the '1932 concordat amounts to a self-denying ordinance by the Treasury ${ }^{60}$, which would be respected 'in the interests of constitutional propriety ${ }^{361}$. Or, to take a more recent example, prior to the enactment of the Constitutional Reform Act 2005, there was a concordat between the Lord Chief Justice and the Lord Chancellor concerning the latter's judiciary-related functions. This concordat remains 'of great constitutional importance ${ }^{62}$, despite being partially superseded by the 2005 Act. Lord Phillips said '[i]t has ... been treated as if it were a constitutional document laying down the division of functions' ${ }^{63}$

None of these examples could ground a bottom-up convention on their own. Together, though, they amount to a practice that stretches back almost 150 years. This practice consists of governmental institutions making formal representations to each other; of these institutions living up to their representations; and of the acceptance they they ought to do so. That is enough to conclude that there is a bottom-up convention that institutions ought to fulfil their representations to each other. By making representations to each other, institutions trigger this convention, creating new norms, and thus new top-down conventions. These self-imposed top-down conventions are agreements. We will call the bottom-up convention that makes them possible the Institutional Agreement Convention. To return to our original example, the Supreme Court and the Ministry of Justice made a constitutional agreement by triggering the Institutional Agreement Convention.

\section{Convention Structures}

\footnotetext{
${ }^{60}$ Select Committee on the Constitution, The Pre-emption of Parliament HL 165 (2012-2013) at [13]

61 ibid.

62 Select Committee on the Constitution, Relations Between the Executive, the Judiciary, and Parliament HL 151 (2006-2007) at [13].

63 ibid at [14].
} 
At this point we have shown that there are top-down conventions which issue from bottom-up conventions. ${ }^{64}$ Let us say that a bottom-up convention and the top-down conventions that issue from it form an interlocking convention structure, or convention structure for short ${ }^{65}$. The conventions that make up the structure are its elements. As well as being the home of top-down conventions, convention structures have other interesting features, of which we shall mention two.

First, the elements in convention structures are mutually reinforcing. The bottom-up element in a convention structure requires compliance with the top-down elements. It supports, or backs, the top-down elements in the same structure. To comply with a top-down convention is not only to comply with that convention; it is also to comply with the bottom-up convention that is part of the same structure. At the same time, a bottom-up convention depends on a practice. That practice is partly constituted by compliance with the bottom-up convention, and hence by compliance with the top-down elements of the same structure. When those top-down elements are complied with, the bottom-up element is strengthened. Conversely, violations of topdown conventions weaken the bottom-up elements of the same structure. So, the top-down elements in a convention structure are backed by the bottom-up element, while compliance with the topdown elements sustains the bottom-up element.

Second, convention structures are resilient, in that they can withstand localized or concentrated non-compliance. A bottom-up

\footnotetext{
${ }^{64}$ A clarification: Rules are norms, as are orders. Rules regulate general acts; orders regulate specific acts. Because conventions are rules, and our interest is conventions, we have focused on powers to make rules of a constitutional character. But there are also powers to make orders of a constitutional character. The Cardinal Convention is one example. The ministers' directives are binding on the monarch. One reason we regard the ministers' directives as binding on the monarch is that we want them to have a way to bind the monarch. So the Cardinal Convention confers authority on ministers over the monarch. The ministers' directives are not conventions (because they are not rules), but they are still binding norms, made possible by the bottom-up convention that is the Cardinal Convention.

${ }^{65} \mathrm{~T}$. Honoré uses the term 'interlocking structure' to describe the relationship between social norms and the norms created under them in Making Law Bind: Essays Legal and Philosophical (Oxford: Oxford University Press, 1987) 83.
} 
convention is a social rule, so it exists only as long as it is generally complied with. Top-down conventions are not social rules, and they exist only as long as the bottom-up convention in the same structure continues to exist. In the convention structures we have described, there is a bottom-up convention and multiple top-down conventions. Imagine one top-down convention in such a structure is generally broken. If there is general compliance with enough other top-down conventions in that structure, then there is general compliance with the bottom-up convention in that structure. The structure as a whole is maintained, and all the conventions in it survive - including the top-down convention that is generally broken. Thus, the Sewel Convention would be binding even if it were generally broken, as long as agreements between institutions were generally kept, and it was generally accepted that they ought to be kept. ${ }^{66}$

We have so far shown that top-down conventions are a reality, contrary to what is often claimed. Now, we turn to the legitimacy of top-down conventions and of conventional regulation generally.

\section{LEGITIMACY AND CONVENTIONAL REGULATION}

How desirable is it that the British constitution relies so heavily on non-legal regulation of the various kinds we have just discussed? This question has received, as McHarg observes, 'curiously little attention from constitutional lawyers' ${ }^{67}$ It is neglected in favour of other (important) questions: about the nature, bindingness, and existence of conventions, detailed examination of the content and development of particular conventions, or the contrast between conventions and law. Barber suggests that the latter is of 'especial' importance in the United Kingdom due to 'the unusual significance and quantity of conventions in the United Kingdom's

66 Partly for this reason, convention structures are susceptible to manipulation. Suppose the Prime Minister wishes to bolster his power to create binding rules for ministers. It will be in the Prime Minister's interests to add some rules to the Ministerial Code that require acts that Ministers would have performed anyway. Why? Because the Prime Minister's power to create binding rules for ministers depends on general compliance with the rules he makes. He can increase the rate of compliance by requiring some 'popular' acts.

${ }^{67} \mathrm{n} 26$ above, 856. 
constitution $^{68}$. But for that same reason, the legitimacy question is also especially important; the legitimacy of a core method of regulating the power of the state should be at the centre of constitutional analysis. Moreover (and this is the reason McHarg considers the neglect to be 'curious') conventions raise particularly pressing legitimacy questions. That is because conventions are a form of self-regulation in a field where that might seem wholly and obviously inappropriate. Constitutionalism essentially requires the regulation of constitutional actors whereas self-regulation raises the spectre of self-interested partisanship. As Peter Cane once said, 'those actively engaged in an activity might be inclined to run it in a way which suits them' as it is clearly an advantage to the regulated to be able to decide the rules of the game. The obvious disadvantage of this is that the rules made may not properly protect the public interest. ${ }^{69}$ This concern strikes us as particularly pressing in the constitutional context; whilst self-regulation is desirable in many contexts it is, on the face of it, the antithesis of constitutionalism, and the legitimacy of constitutional conventions ought to have attracted more sustained attention. ${ }^{70}$

One consequence of our argument so far is that there is not one neglected legitimacy question but two. Instead of asking is conventional regulation legitimate?', we should ask whether bottom-up conventional regulation is legitimate and whether topdown conventional regulation is legitimate. We take up both of these questions below. Our aim is not to develop a full blooded account of the legitimacy of either species of convention. Instead we aim to identify normatively salient features of bottom-up and top-down conventions to encourage reflection and further conversation on the legitimacy of conventional regulation. We suggest that neglect of the legitimacy question is understandable with respect to bottom-up conventions, but that there are good reasons to be cautious (suspicious, even) with respect to top-down conventions.

\footnotetext{
${ }^{68} \mathrm{n} 46$ above, 294.

${ }^{69}$ P. Cane, 'Self Regulation and Judicial Review' [1987] Civil Justice Quarterly 324, 325,329

70 And, as McHarg notes, 'constitutional lawyers ... have tended to be suspicious of the legitimacy of self-regulatory practices in other contexts': n 26 above, 856 .
} 


\section{Legitimacy and Bottom-Up Conventions}

Two facts about bottom-up conventions make inattention to their legitimacy less surprising. First, they fill a regulatory vacuum which would otherwise be embarrassing. Grateful that the vacuum has been filled, we tend not to ask about the desirability of it being filled in this way. Instead, we focus on other questions. For example, both Jennings and Jaconelli are interested in the conditions under which a convention exists. ${ }^{71}$ Barber, meanwhile, is concerned with the differences between conventions and the form of regulation we might have expected to be using, namely, laws. ${ }^{72}$ There is interest in establishing that a vacuum has been filled, and in how it has been filled. But interest in those questions stops short of engagement with the desirability of filling a vacuum in a particular, self-regulatory way.

Second, the subject matter and effect of the most prominent cluster of constitutional conventions is overwhelmingly positive. For example, the Cardinal Convention is part of a prominent cluster of conventions which secure the (de facto) transfer of much prerogative power from the monarch to ministers and which curtail any discretion in her exercise of her remaining personal prerogative power (like the Royal Assent and appointment of ministers). This development of 'constitutional rules that limit the powers of the monarch such that we live in a democracy rather than a dictatorship ${ }^{, 73}$ is self-evidently desirable. Conventions might be an idiosyncratic method of securing that particular development, but the development itself obviously stands in no real need of defence. These are key examples of conventions, and the need for evaluation of conventional regulation as a technique is obscured.

So much, so obvious. But bottom-up conventions also have other important features which help shield them from criticism. What follows should not be understood as a list of necessary characteristics of bottom up conventions. Rather it is a list of characteristics which bottom up conventions typically have. A

\footnotetext{
71 Jennings n 8 above; Jaconelli n 7 above.

72 n 46 above.

73 A. Tucker, 'Constitutional Writing and Constitutional Rights' [2013] PL 345, 351.
} 
paradigmatic or central case of a bottom-up convention might well have them all (in fact, we think such central cases exist, for example, the convention requiring the Queen to grant Royal Assent to duly passed legislation). But other, less typical, bottomup conventions with fewer of these characteristics exist as well. With those caveats in place, five characteristics are worth dwelling on.

1. Bottom-up conventions are not made intentionally. Bottom-up conventions typically arise from people's behaviour. However, whilst that behaviour is (we would expect) itself intentional, it is not behaviour which is engaged in with the intention of creating or changing rules. For example, in systematically giving Royal Assent to legislation passed by the Houses of Parliament, monarchs were of course intentionally and deliberating attempting to assent to legislation. But none of these successive assents were intended to create a rule. Similarly, the repeated appointments as Prime Minister of the person most able to command a majority in the House of Commons were intended (merely) as appointments, rather than attempts to create or change a rule about who ought to be appointed. In time, of course, such intentions can become ruleoriented, as actors orient their behaviour to the rule. But then the intention is essentially an intention to conform to the rule, rather than to make or change it. In this way, ministers who have resigned in consequence of a breach of the convention of ministerial responsibility do have an intention about a rule. They may even be conscious that their behaviour reinforces the rule. But the relevant intention is that of conforming to, not making or remaking the rule itself. So bottom-up conventions emerge, unintentionally and hence accidentally, from the underlying behaviour. They are not intentionally created. And so the risk that they will be used to create damaging, self-interested rules is attenuated.

2. Bottom-up conventions are not made expressly. Bottom-up conventions typically emerge from and exist in people's behaviour, rather than in and from their words. One consequence of this is that they have no canonical formulation. This means that understanding (interpreting) the rule is not tied to particular words. Flexibility is 
not necessarily a virtue, but the kind of flexibility introduced by this feature of conventions is important because it is much harder to bind your successors to an undesirable, self-interested rule if you cannot fix the rule in a canonical formulation.

These first two characteristics together have an important consequence, which it is worth pausing to highlight. They are the main source of the (famous) characteristic vagueness of conventions, which is hence like the vagueness of social rules. ${ }^{74}$ As they develop, rules which are made neither intentionally nor expressly are untethered from their creators (for there is neither intention nor formulation to tether them to), and their development depends on the behaviour of the current generation of rule-users. And that behaviour is driven by those rule-users' understanding of the contemporary rationale of the rule. $^{75}$ Consider, for example, the indeterminacy in the constitutional convention governing Royal Assent. There is even today some uncertainty whether this convention eliminates entirely the monarch's veto over legislation or whether some discretion subsists so the veto could still be exercised in exceptional circumstances. Brazier, for example, has speculated that there are some scenarios in which the exercise of the royal veto may still be constitutionally proper, not just on ministerial advice (after a change of government, ministerial opposition to a private member's bill) but even against ministerial advice (serious legislative impropriety, legislation prolonging Parliament's life and legislation permanently subverting the democratic basis of the constitution). ${ }^{76}$ So there is indeterminacy in the rule, and the outcome in scenarios where it matters would depend neither on any previous monarch's intention about such situations, nor on a previous monarch's formulation of a rule covering such situations. It would depend on the present monarch's own understanding of the nature of her obligation. This type of vagueness detaches the

\footnotetext{
${ }^{74}$ Governance of Britain $\mathrm{n} 22$ above, ch 7.

75 A. Tucker, 'Uncertainty in the Rule of Recognition and in the Doctrine of Parliamentary Sovereignty' (2011) 31 OJLS 61.

76 R. Brazier, 'Royal Assent to Legislation' (2013) 129 LQR 184, 201-202.
} 
requirements of the rule from its creation and redirects the focus of controversy to contemporary concerns.

3. Bottom-up conventions have diffuse authorship. Bottom-up conventions are typically role-centred conventions. They arise out of the behaviour of multiple people, each occupying the same or similar roles, but at different times, with different partisan and personal interests, and in shifting political circumstances. So whilst the creation of the rule is a collective enterprise, the creative behaviour is not coordinated or part of any kind of joint project. It consists of actions which are distinct from each other, rather than part of a long, communal rule-making enterprise. There is no common project. As John Gardner says (of customary law, but the point is true here too): conventions are "not the work of many working as one ... [they are] ... the work of many acting as many. ${ }^{, 77}$.

4. Bottom-up conventions are asystematic. Barber, following Colin Munro, emphasises that conventions typically have a kind of informality. ${ }^{78}$ By informality, Barber and Munro mean that constitutional conventions form a 'discrete unconnected set ${ }^{79}$ in the sense that they are not embedded in a wider system of rules. There is 'no authoritative mark of their existence, no rules which determine whether or not political actors ought to regard them as binding $\ldots$ no rules which regulate their production, no institutions to adjudicate upon their breach. ${ }^{80}$ Barber concedes that 'it would obviously be going too far to claim that conventions are completely non-systematic' on the grounds that 'it is actually quite hard to conceive of a social rule which does not, in some way, rely on or interact with other rules ${ }^{81}$. But mere interaction or haphazard inter-reliance is a particularly weak form of

\footnotetext{
77 J. Gardner, 'Some Types of Law' in D. Edlin (ed), Common Law Theory (Cambridge: Cambridge University Press, 2007) 23.

78 n 46 above, 302, citing C. Munro, 'Laws and Conventions Distinguished' (1975) 91 LQR 218, 233.

${ }^{79}$ Munro n 78 above, 233.

${ }^{80}$ Barber $\mathrm{n} 46$ above, 302.

81 ibid.
} 
systematicity. ${ }^{82}$ It has nothing to do with the nature of bottom-up conventions as a form of regulation. We can see this through Jennings' Test, which is (rightly) blind to the systematicity of the rules whose existence it seeks to capture. Conventions of the same constitution inevitably interact with each other, yet they exist and are constituted independently of each other.

5. Bottom-up conventions are self-regarding. Finally, bottom-up conventions do not impose obligations on people other than those whose behaviour creates them. More precisely, they tend to be (what we called above) role-centred, regulating only people occupying the same role as made them and regulating them only insofar as their actions are performed in that role. Conventions which emerge from Prime Ministerial behaviour regulate only Prime Ministers, and conventions which emerge from the behaviour of monarchs regulate only monarchs. The actors involved only acquire the power to regulate their own (and their successors') behaviour rather than extend their regulatory influence to other actors in the constitutional system. For example, the existence of a convention on Royal Assent - created by and applicable to monarchs - might superficially give reason to worry about the consequences of giving the monarch a power to regulate the outcome of the legislative process. But, more precisely, the monarch only acquires through this convention a (more circumscribed, narrowly focussed) power to regulate the monarch's involvement in the outcome of the legislative process.

Individually, each of these five features helps to counter the objection from self-regulation. Together, though, these features are significant enough to explain (and maybe even to justify) constitutional lawyers' relative inattention to the question of the legitimacy of bottom-up conventions, despite them being an otherwise surprisingly important instance of self-regulation at the heart of the constitution.

\section{Legitimacy and Top-Down Conventions}

82 Indeed, as we have just seen, Barber's own account of systematicity (quoted ibid) is substantially richer than that. 
As may have already become clear, this cluster of redeeming characteristics is not shared by top-down conventions, which thus cannot claim even the modest virtue of bottom-up conventions. In fact, quite the opposite. Again, we do not intend this section as a list of necessary characteristics of top-down conventions. Rather it is a group of characteristics which top-down conventions typically have. A paradigmatic or central case of a top-down convention might well have them all but other, less typical, top-down conventions with fewer of these characteristics exist as well, without forfeiting their basic status as top-down conventions. With those caveats once more in place, these characteristics are worth dwelling on at length.

1. Top-down conventions are intentionally made. Top-down conventions do not emerge accidentally or unintentionally from behaviour. Instead, they are typically the product of an intentional attempt to make a rule. For example, the actors who collectively generated the Sewel Convention could not be said to have been participating in the practice of securing the consent of the Scottish Parliament before legislating on reserved matters. Their actions were about rather than a part of that activity - directed, and intentionally so, towards the articulation and institutionalisation of a rule binding those who do participate in the legislative process. Similarly, when the Prime Minister publishes a new version of the Ministerial Code, he is obviously not simply participating in the practices which it describes. Rather, her intention is to attach binding force to the rules it contains.

2. Top-down conventions are expressly made. Unlike bottom-up conventions, top-down conventions do not emerge; rather they are made. More precisely, they are created in words, in a text. This means that they have a canonical formulation and their meaning is tied to those words. For example, the Sewel Convention originates in (the text of) Lord Sewel's speech in the House of Lords; it is further specified in (the text of) the Memorandum of Understanding between the UK and Scottish Governments and its requirements are more concretely articulated in (the text of) Devolution Guidance 
Note 10 (DG10). ${ }^{83}$ Controversy about the scope of the Sewel convention thus takes place primarily in the light of the requirements of those texts. It would, therefore, be essentially implausible to argue that something which these texts requires was not, after all, required by the Convention.

Consider, for example, the important contemporary controversy about the scope of the Sewel Convention. Lord Sewel initially promised a convention which would apply whenever Westminster legislates 'with regard to devolved matters ${ }^{84}$. But note that this promise, and the notion of 'legislating with regard to' is ambiguous about whether the Convention's demands extend only to legislation which regulates matters which are currently devolved, or whether it also extends to legislation changing what counts as a devolved matter - that is, there is an ambiguity about whether the Sewel convention is restricted to legislation which ('merely') trespasses upon the devolution settlements as they stand or whether it also extends to legislation amending the devolution settlements themselves. DG10 explicitly takes sides in this controversy by characterising the Convention as applicable to legislation altering the competences of the Scottish Parliament or of the Scottish Ministers. And debate about the convention is constrained by this textual foundation. Consider, for example, the parliamentary debate on (what is now) section 2 of the Scotland Act 2016, which aims to put the Sewel Convention on a statutory footing and whose text reflects the briefer, ambiguous version of the convention. During its passage through Parliament, the Government (successfully) resisted amendments which sought to expand this provision into articulating the more explicitly broad understanding of the convention found in DG10. But, importantly, this resistance was not on the grounds that this would not faithfully capture the requirements of the convention. ${ }^{85}$ The textual

\footnotetext{
${ }^{83}$ UK Cabinet Office, Devolution Guidance Note 10: Post-devolution primary legislation affecting Scotland; Memorandum of Understanding and Supplementary Agreements between the United Kingdom Government, the Scottish Ministers, the Welsh Ministers, and the Northern Ireland Executive Committee (October 2013)

${ }^{84}$ HL Deb vol 592 col 79121 July 1998.

85 Proposed amendments to this effect were resisted on the grounds that "the bill adopt[ed] the language that formed the basis of the Sewel Convention"
} 
nature of the convention, and the way it is articulated in DG10 would have made such an argument implausible. Conversely, it is extremely difficult to argue that something which the texts do not require is part of the Convention.

Again, one upshot of these two features of top-down conventions is best appreciated by considering them together. Top-down conventions are vague, but they are vague in a different way to bottom-up conventions. Their meaning is tethered to the intentions of their creators, and the language which those creators use to express the rule. In other words, theirs is the vagueness of written rules rather than of social rules.

For example, consider the Salisbury-Addison convention. In a speech in the House of Commons in 2006, Chris Bryant MP conceived of this rule as intentionally created and written, and characterised the controversy about its content as a choice between two conceptions of the rule - one 120 years old, and the other formulated in 1947. His argument was about where the convention is tethered, but takes for granted that it must be tethered somewhere, in a way that determines its contemporary meaning. ${ }^{86}$ This empowers the actors responsible for that formulation as who thereby have an enhanced role in fixing the meaning of the rule.

Or, consider again the ambiguity about the scope of the Sewel convention. In $\mathrm{R}$ (Miller) v Secretary of State for Exiting the European Union, the Supreme Court declined not just to enforce the Sewel Convention, but also to interpret it or rule on its scope. ${ }^{87}$ But the court did describe evidence for the broader of the two rival understandings of the convention - that is, a pattern of legislative

which had been "consistently adhered to by successive UK governments". See in the speech(es) of D. Mundell MP at HC Deb vol 597 col 10515 June 2015.

${ }^{86}$ HC Deb, 20 June 2006, c366. Note that we conceive of this particular convention differently, above, as a bottom-up convention which arose over time under the influence of Lord Salisbury and Lord Addison's original accord. If we are correct, then Bryant was mistaken to use the rule in this way; but our example here turns on the way he engaged with the rule, and not whether he was ultimately correct to approach it that way.

${ }^{87}$ R (Miller and others) v Secretary of State for Exiting the EU 2017 UKSC 5, 20172 WLR 583. at [136]-[151] (DC). 
consent motions for statutes amending the devolution settlements. $^{88}$ Alison Young has described this intervention into the controversy in the following terms:

the court is observing the broader application of the Sewel Convention. The court is not creating this broader interpretation, it being instead created by the behaviour of the UK Parliament and the devolved legislatures. ${ }^{89}$

But we think this mischaracterises the nature of the convention, and also the way in which the controversy stands to be settled. The behaviour the court described - a pattern of legislative consent motions for statutes amending the devolution settlements - did not create the rule. In fact, that behaviour can only properly be understood by taking into account the fact that each of the examples referred to by the court was not simply freestanding behaviour of the UK Parliament and the devolved legislatures, but rather behaviour shaped and constrained by the demands of a written rule intended to bind them to behave in that way.

3. Top-down conventions are the product of coordination. Gardner says this about the way teamwork emerges in orchestras and legislatures, and how that unites their participants in a single agent:

In teamwork, each team-member adapts her intentions to the actions and intentions of the others so as to avoid frustrating each other's intentions. But that is not all. Each team member also adds an extra intention, that of contributing to the work of the team as a whole. She intends not only that she (and each of the others) should make their complementary efforts, but that this should also be part of a team effort. So her own intention makes an essential reference to the intention of the team. When it does so, it also helps to constitute the intention of the team. ${ }^{90}$

\footnotetext{
88 ibid at [140].

${ }^{89}$ A. Young, 'R (Miller) v Secretary of State for Exiting the European Union: thriller or vanilla?' (2017) 42 European Law Review 280, 287.

${ }^{90} \mathrm{n} 77$ above, 58.
} 
It would be going too far to describe the creators of top-down conventions as a single unified agent. Still, the degree to which the authorship of top-down conventions approaches this model is striking. They are the product of a kind of joint agency, whose members are responsive to each others' intentions (intentions, recall, about the creation of a rule). The creation and development of these norms has a dimension of commonality and coherence. Recall the complex authorship of the Sewel Convention: its creators were clearly acting in concert in the enterprise of rulemaking.

4. Top-down conventions are systematic. Barber recognises that topdown conventions are a sign of growing formalisation. Indeed this is central to his argument that there is a scale of formality stretching from conventions to law and that the move to topdown conventions is a move to a more formal (and hence more law-like) type of regulation. As we explained above, systematicity is inherent to the nature of top-down conventions as they exist in interlocking convention structures (which are themselves a simple system) which reinforce each other, leading to reciprocal (and hence systematic) resilience. Furthermore, individual top-down conventions are prone to their own, individualised, formality. We see this clearly in the example of Baroness Warsi's visit to Pakistan, which the Prime Minister referred to the Independent Adviser on Ministers' Interests. The rule against conflicts of ministerial interests, is not simply captured in the text of the Ministerial Code. It is now accompanied by an institution competent to adjudicate (albeit in this instance non-authoritatively) on its breach.

5. Top-down conventions are other-regarding. Finally, note that the obligations which are created by top-down conventions are typically imposed on actors other than the actors who create them. They involve Prime Ministers regulating (in the Ministerial Code) ministers or ministers and civil servants regulating (in the Sewel Convention) the legislature. Thus, top-down conventions are the product of certain constitutional actors imposing binding obligations on others, without regard for role, hierarchy or legitimacy. Again, the Sewel Convention is particularly striking: it 
was developed by the executive yet binds the democratic legislature.

\section{Cause for Concern}

We started by noting an objection to conventional regulation: as a form of self-regulation, conventional regulation seems to be prima facie illegitimate. Bottom-up conventions have a number of features which help address the objection from self-regulation. But top-down conventions are different. Top-down conventions are made deliberately, expressly, and by a single actor or group of actors working in concert. They are formal, hierarchical, and systematised. They are a way of exercising authority and extending power. If anything, top-down conventions seem to exacerbate our concerns about conventional regulation. It is perhaps understandable that bottom-up conventions have tended to avoid serious normative scrutiny, but top-down conventions warrant closer examination than they have received so far.

This dichotomy - bottom-up conventions as innocuous or welcome, top-down conventions as essentially suspect - is too neat however. It needs complicating in one important respect. Topdown conventions are grounded in the use of a normative power, and such powers are conferred by bottom-up conventions. Thus, while most bottom-up conventions are innocuous or welcome, a few bottom-up conventions lay the groundwork for deliberate, concentrated, systematic regulation, and help to consolidate power in the hands of a relatively small number of constitutional actors (eg, the Prime Minister). For all the reasons we should be wary of top-down conventions, we should be wary of the bottom-up conventions which confer the powers to create them.

\section{SUMMARY AND CONCLUSION}

No-one doubts the existence of bottom-up conventions, but many scholars doubt the existence of top-down conventions. Here we have offered a novel argument for the reality of top-down conventions. Top-down conventions are the exercise of normative powers conferred by social rules of the constitution, ie, bottom-up 
conventions. There are at least two such bottom-up conventions, which have so far gone unnoticed. The Institutional Agreement Convention empowers government institutions to make binding commitments to each other. The Ministerial Code Convention empowers the Prime Minister to create rules for ministers by amending the Code. The powers conferred by these bottom-up conventions have been used to create many top-down conventions.

Given the centrality of conventions in the British constitution, surprisingly little attention is paid to the legitimacy of regulation by convention. We put forward the beginning of an explanation, by identifying five central features of bottom-up conventions. These features serve as a normative safety net, excusing and possibly even justifying reliance on bottom-up conventions. But top-down conventions do not share these features. Top-down conventions are the formal, systematic, intentional products of concentrated power and authority. There is no reason to be sanguine about topdown conventions as a form of constitutional regulation; indeed, there is reason for concern.

Let us end on a positive, forward-looking note. To the extent that there is a problem with top-down conventions, the source of that problem is the bottom-up conventions which confer the powers to create them. As we said, bottom-up conventions depend on acceptance by constitutional actors. Acceptance is an attitude which is responsive to practical reasons, and which is under one's voluntary control. What this means is that top-down conventions are not something we are stuck with. If constitutional actors decide that top-down conventions have had negative consequences, they can do away with the bottom-up conventions which make them possible. All they need to do is decide not to accept that certain constitutional actors have the power to deliberately bind themselves or others. We do not mean to diminish the difficulty of changing our mode of constitutional regulation. The point remains: constitutional actors created the powers under which topdown conventions are created - and constitutional actors can dispense with those powers, if they will it. 